\title{
A novel Surface Complexation Model approach to account for substitution in minerals: A case study of aluminum-ferrihydrites
}

\author{
F. T. ADAMS ${ }^{1}$, M. L. MACHESKY ${ }^{2}$, N. KABENGI ${ }^{1}$
}

${ }^{1}$ Dept. of Geosciences, Georgia State University, Atlanta,

GA, USA (*correspondence: fadams4@student.gsu.edu)

${ }^{2}$ Illinois State Water Survey, Prairie Research Institute,

Champaign, IL, USA (machesky@illinois.edu)

Surface Complexation Models (SCMs) have been utilized to describe charging and sorption on a host of mineral surfaces to great success. While SCMs have been updated to account for higher temperatures [1] and complex minerals such as ferrihydrite [2], they have not, for the most part, accounted for site defects and substitutions. Previous attempts to describe sorption on minerals containing impurities have utilized a uniform affinity constant for the mineral surface without breaking down the contribution of individual surface sites. The resulting models are constrained for a specific set of conditions and do not apply to the amalgam of scenarios found in the environment. In this study, we propose a new approach to building SCMs that takes into account the location of the substitution and demonstrate its applicability to aluminum ( $\mathrm{Al})$ substitution in ferrihydrite $(\mathrm{Fh})$. $\mathrm{Fh}$ is a ubiquitous iron oxyhydroxide in natural environments. The debate around its structure is complicated by the presence of impurities, such as $\mathrm{Al}$, that is known to substitute for Iron $(\mathrm{Fe})$ in $\mathrm{Fh}$.

Our approach situates the $\mathrm{Al}$ into octahedrallycoordinated reactive $\mathrm{Fe} 1$ sites that are bound to hydroxyls and are on the surface of the mineral. The Al substituted Fh (Al-Fh) samples synthesized have $12 \%$ and $24 \% \mathrm{Al}$, by molar weight. In the model, we modified the properties of the surface sites (site densities and affinity constants) to account for the presence of $\mathrm{Al}$ on the new surface. We used the Charge Distribution - MultiSite Complexation (CD-MUSIC) model paired with the Basic Stern layer model to describe the zeta potential of pure and $\mathrm{Al}-\mathrm{Fh}$ as a function of solution pHs. The resulting model produced calculated values that satisfactorily fit the measured empirical data. We posit that this approach will serve as a foundation for building SCMs that account for environmental complexities.

\section{REFERENCES}

[1] Machesky et al. (2015), J. Phys. Chem. C 119 (27) 15204-15215.

[2] Bompoti et al. (2016), Chem. Geol. 464, 34-45. 